\title{
Pelatihan Pengujian In-Situ Tanah bagi Laboran Muda Mekanika Tanah
}

\author{
Susy Srihandayani ${ }^{1}$, Fitridawati Soehardi*2 ,Lusi Dwi Putri ${ }^{3}$, Winayati ${ }^{4}$ \\ ${ }^{1}$ Program Studi Teknik Sipil, Sekolah Tinggi Teknologi Dumai \\ 2,3,4Program Studi Teknik Sipil, Fakultas Teknik, Universitas Lancang Kuning \\ *e-mail: gadisoil79@gmail.com¹, fitridawati@unilak.ac.id ${ }^{2}$, lusidwiputri@unilak.ac.id² \\ winayati@unilak.ac.id ${ }^{4}$
}

\begin{abstract}
The in-situ test is a method of geomechanical testing that is carried out directly in the field, without taking samples for the laboratory. The low interest of laboratory staff in exploring the area of soil mechanics, especially soil testing both in the area and in the laboratory. This is because the laboratory staff considers that developing expertise in testing equipment and processing soil mechanics data is quite tricky and expensive. HIMATESI is a student association consisting of young researchers, young laboratory assistants, or final year students conducting research and testing of soil mechanics. Partners recognize the need for increased understanding of In-Situ soil testing.But on the other hand, it becomes a fear of its own for partners about solving problems that arise in In-Situ soil testing during implementation in the field. Universities answer partner problems by providing knowledge about In-Situ soil testing and training on the use of In-Situ soil testing equipment and tricks to deal with issues in In-Situ soil testing for free In-Situ soil testing. Community service activities in the form of In-Situ Soil testing training for soil mechanics laboratory assistants were held to provide information on the introduction and use of In-Situ testing tools such as the Dynamic Cone Penetrometer, Handbore Tool and Sandcone Tool. The results of this training were able to increase the participants' knowledge of the use of soil In-situ testing tools and tricks in overcoming problems in the field with the help of In-situ tools. It is hoped that the participants can implement the knowledge gained in-field implementation later.
\end{abstract}

Keywords: Training, In-Situ Soil testing, laboratory.

\begin{abstract}
Abstrak
In-situ test adalah salah satu metode pengujian geomekanika yang pelaksanaannya dilakukan langsung di lapangan, tanpa pengambilan percontoh untuk laboratorium. Rendahnya minat laboran dalam mendalami bidang mekanika tanah khususnya pengujian tanah baik di lapangan maupun di laboratorium. Hal ini di sebabkan oleh para laboran menganggab bahwa pengembangan keahlian dalam menggunakan peralatan pengujian dan pengolahan data mekanika tanah cukup sulit dan mahal. HIMATESI merupakan sebuah himpunan mahasiswa yang beranggotakan para peneliti muda, laboran muda atau mahasiswa tingkat akhir yang sedang melakukan penelitian dan pengujian mekanika tanah. Mitra menyadari perlu peningkatan pemahaman tentang pengujian In-Situ tanah. Namun disisi lain menjadi ketakutan tersendiri bagi mitra tentang penyelsaiaan permasalahan yang timbul dalam pengujian In-Situ tanah pada saat pelaksanaan dilapangan. Perguruan tinggi menjawab persoalan mitra dengan memberikan pengetahuan tentang pengujian In-Situ tanah dan pelatihan penggunaan peralatan pengujian In-Situ tanah serta trik-trik menhadapi permasalahan dalam pengujian In-Situ tanah pengujian In-Situ tanah secara gratis. Kegiatan Pengabdian masyarakat dalam bentuk pelatihan pengujian In-Situ Tanah bagi laboran mekanika tanah yang diadakan bertujuan untuk memberikan bekal informasi tentang tentang pengenalan dan penggunaan alat pengujian In-Situ seperti Dynamic Cone Penetrometer, alat Handbore dan alat Sandcone. Hasil pelatihan ini mampu meningkatkan pengetahuan peserta terhadap penggunaan alat pengujian In-situ tanah dan triktrik dalam mengatasi permasalahan dilapangan terhadap penggunaan alat Insitu sehingga diharapkan para peserta dapat mengimplementasikan ilmu yang di dapat dalam pelaksanaan dilapangan nantinya.
\end{abstract}

Kata kunci: Pelatihan, pengujian In-Situ Tanah, laboran

\section{PENDAHULUAN}

In-situ test adalah salah satu metode pengujian geomekanika yang pelaksanaannya dilakukan langsung di lapangan, tanpa pengambilan percontoh untuk laboratorium (N \& MS, 2017). Pengujian In-situ tanah (Kementrian PUPR, 2021)di lapangan terdiri dari beberapa tahapan yaitu: 
1. Pemboran inti /core drilling/boring adalah pekerjaan yang mengambil contoh tanah untuk mengetahui lapisan tanah dan untuk mengambil contah tanah yang akan di uji di laboratorium (Malauw, Sidik, \& Pramudito, 2018).

2. Uji Conus/Sondir adalah Uji untuk mengetahui nilai tahanan konus (qc) terhadap konsistensi tanah (Prayogo \& Saptowati, 2016).

3. DCP atau Dynamic Cone Penetrometer (Permatasari, 2018) adalah alat yang digunakan untuk mengukur daya dukung tanah dasar jalan langsung di tempat. Daya dukung tanah dasar tersebut diperhitungkan berdasarkan pengolahan atas hasil test DCP yang dilakukan dengan cara mengukur berapa dalam (mm) ujung konus masuk ke dalam tanah dasar tersebut setelah mendapat tumbukan palu geser pada landasan batang utamanya. Korelasi antara banyaknya tumbukan dan penetrasi ujung conus dari alat DCP ke dalam tanah akan memberikan gambaran kekuatan tanah dasar pada titik-titik tertentu(Lengkong, Monintja, Sompie, \& Sumampouw, 2013). Makin dalam konus yang masuk untuk setiap tumbukan artinya makin lunak tanah dasar tersebut. Pengujian dengan menggunakan alat DCP akan menghasilkan data yang setelah diolah akan menghasilkan CBR lapangan tanah dasar pada titik yang ditinjau. Khusus untuk perencanaan jalan raya kekuatan tanah dasar ditandai dengan meningkatnya nilai CBR (California Bearing Ratio) dari tanah tersebut (Sukirman, 1999).

4. Pengujian CBR(J.E.R. Sumampouw, 2010) adalah perbandingan antara beban penetrasi suatu bahan terhadap bahan standar dengan kedalaman dan kecepatan penetrasi yang sama. Nilai CBR dihitung pada penetrasi sebesar 0.1 inci dan penetrasi sebesar 0.2 inci dan selanjutnya hasil kedua perhitungan tersebut dibandingkan sesuai dengan SNI 03-1744-1989 diambil hasil terbesar. Tujuan dilakukan pengujian CBR ini adalah untuk mengetahui nilai CBR pada variasi kadar air pemadatan.

5. In situ Density test disini yakni merupakan tes kepadatan tanah, ada banyak cara untuk melakukan tes kepadatan ini, salah satunya dengan menggunakan pasir(Hadijah, 2015).

Rendahnya minat laboran dalam mendalami bidang mekanika tanah khususnya pengujian tanah baik di lapangan maupun di laboratorium. Hal ini di sebabkan oleh para laboran menganggap bahwa pengembangan keahlian (Yanti, Zainuri, \& Megasari, 2017) dalam menggunakan peralatan pengujian dan pengolahan data mekanika tanah cukup sulit dan mahal. Sungguh ironis jika sampai saat ini masih banyak laboran yang tidak mengetahui dan terkadang salah dalam pengambilan data sehingga berpengaruh dalam pemberian keputusan terhadap data hasil pengujian suatu kegiatan kontruksi. Hal ini yang akan menjadi latar belakang terjadinya permasalahan dan kegagalan kontruksi. Tentu saja hal ini cukup menjadi perhatian kita semua, sehingga menjadi sangat penting bagi kita untuk mengantisipasi tindakan ini.

Berdasarkan hasil diskusi dari beberapa anggota HIMATESI yang para anggotanya berasal dari laboran muda mekanika tanah Program Studi Teknik Sipil yang ada di Pekanbaru dan sedang melakukan penelitian dan pengujian mekanika tanah. Mitra menyampaikan bahwa mereka mempunyai kekhawatiran terhadap pemahaman terhadap penggunaan peralatan pengujian dan penyelesaian permasalahan yang timbul pada saat pengujian In-Situ tanah dilapangan.

Terkait permasalahan mitra yang merupakan Himpunan mahasiswa Teknik Sipil dan laboran muda mekanika tanah yang sedang penelitian dan pengujian berasal dari Program Studi Teknik Sipil yang ada di Pekanbaru. Solusi yang tim kami tawarkan dalam bentuk pengabdian dengan melakukan sosialisi pengenalan pengujian In-Situ Tanah, Pelatihan pengujian In-Situ Tanah (Srihandayani, Studi, \& Dumai, 2019). Tahapan pelatihan yang akan diberikan adalah : Sosialisasi pengenalan alat-alat pengujian In-Situ Tanah,Praktek pengunaan alat- alat pengujian In-Situ Tanah, Pengetahuan tentang trik-trik dalam mengatasi permasalahan pengujian In-Situ Tanah 


\section{METODE}

Metode pendekatan yang digunakan dalam pembelajaran pada pelatihan Pengujian Insitu Tanah bagi laboran muda Mekanika tanah yaitu Ceramah dan Diskusi tentang materi Pengujian In-situ Tanah, On The Job Training (OJT)/Praktik penggunaan alat Pengujian In-situ Tanah dilapangan, Metode praktik ini digunakan dengan tujuan akhir mitra mampu menggunakan pengujian In-Situ Tanah dan memahami Trik-trik dalam mengatasi permasalahan pengujian In-Situ Tanah.

Pengujian In-situ yang dipergunakan pada pelatihan ini adalah pengenalan dan penggunaan alat DCP atau Dynamic Cone Penetrometer, alat Handbore dan alat Sandcone .

Tahapan pelaksanaan kegiatan pengabdian kepada masyarakat masyarakat adalah kegiatan belajar di kelas, dengan materi pembelajaran yaitu :

Tabel 2. Materi Pembelajaran

\begin{tabular}{|c|c|}
\hline Kegiatan Belajar & Materi \\
\hline Kegiatan Belajar 1 & Sosialisasi pengenalan alat-alat pengujian In-Situ Tanah \\
\hline Tujuan & Peserta memahami alat-alat pengujian In-Situ Tanah \\
\hline $\begin{array}{l}\text { Materi atau ringkasan } \\
\text { belajar }\end{array}$ & $\begin{array}{l}\text { Peserta akan diajak untuk mendikusikan beberapa hal yaitu : } \\
\text { - Pengenalan Handbore } \\
\text { - Pengenalan DCP } \\
\text { - Pengenalan sandcone }\end{array}$ \\
\hline Perlengkapan & $\begin{array}{l}\text { - Laptop dan Infocus } \\
\text { - Papan tulis / white board dgn perlengkapannya } \\
\text { - Spidol }\end{array}$ \\
\hline Kegiatan Belajar 2 & Trik-trik dalam mengatasi permasalahan pengujian In-Situ Tanah \\
\hline Tujuan & $\begin{array}{l}\text { Peserta memahami trik-trik dalam mengatasi permasalahan } \\
\text { pengujian In-Situ Tanah }\end{array}$ \\
\hline $\begin{array}{l}\text { Materi atau ringkasan } \\
\text { belajar }\end{array}$ & $\begin{array}{l}\text { Peserta akan diajak untuk mendikusikan beberapa hal tentang cara } \\
\text { trik-trik dalam mengatasi permasalahan pengujian In-Situ Tanah }\end{array}$ \\
\hline Perlengkapan & $\begin{array}{l}\text { - Laptop dan Infocus } \\
\text { - Papan tulis / white board dgn perlengkapannya } \\
\text { - Spidol }\end{array}$ \\
\hline Kegiatan Belajar 3 & Praktik pengujian In-Situ Tanah \\
\hline Tujuan & Peserta mampu menggunakan peralatan pengujian In-Situ Tanah \\
\hline $\begin{array}{l}\text { Materi atau ringkasan } \\
\text { belajar }\end{array}$ & $\begin{array}{l}\text { Peserta akan diajak untuk mendikusikan beberapa hal dalam } \\
\text { menggunakan peralatan pengujian In-Situ Tanah yaitu: } \\
\text { - Pengenalan Handbore } \\
\text { - Pengenalan DCP } \\
\text { - Pengenalan sandcone }\end{array}$ \\
\hline
\end{tabular}

\section{HASIL DAN PEMBAHASAN}

Kegiatan Pengabdian dalam bentuk pelatihan In-situ Tanah bagi lanoran Muda mekanika Tanah ini telah dilaksanakan pada hari jum'at dan sabtu, 10-11 Desember 2021 dengan jumlah peserta 16 orang yang terdiri dari para laboran muda mekanika tanah program studi teknik sipil universitas lancang kuning. Kegiatan ini diisi dengan pemaparan materi pelatihan oleh Narasumber tentang pengetahuan dasar Pengujian In-Situ Tanah. 
Para Peserta sangat antusias dalam mengikuti pelatihan tersebut karena mendapat banyak informasi tentang alat pengujian Insitu tanah dan trik-trik mengatasi permasalahan yang muncul dilapangan terhadap penggunaan alat Dynamic Cone Penetrometer, alat Handbore dan alat Sandcone dilapangan. gambar 1.

Proses Pelaksanaan Penyampaian materi pelatihan In situ Tanahdapat dilihat pada

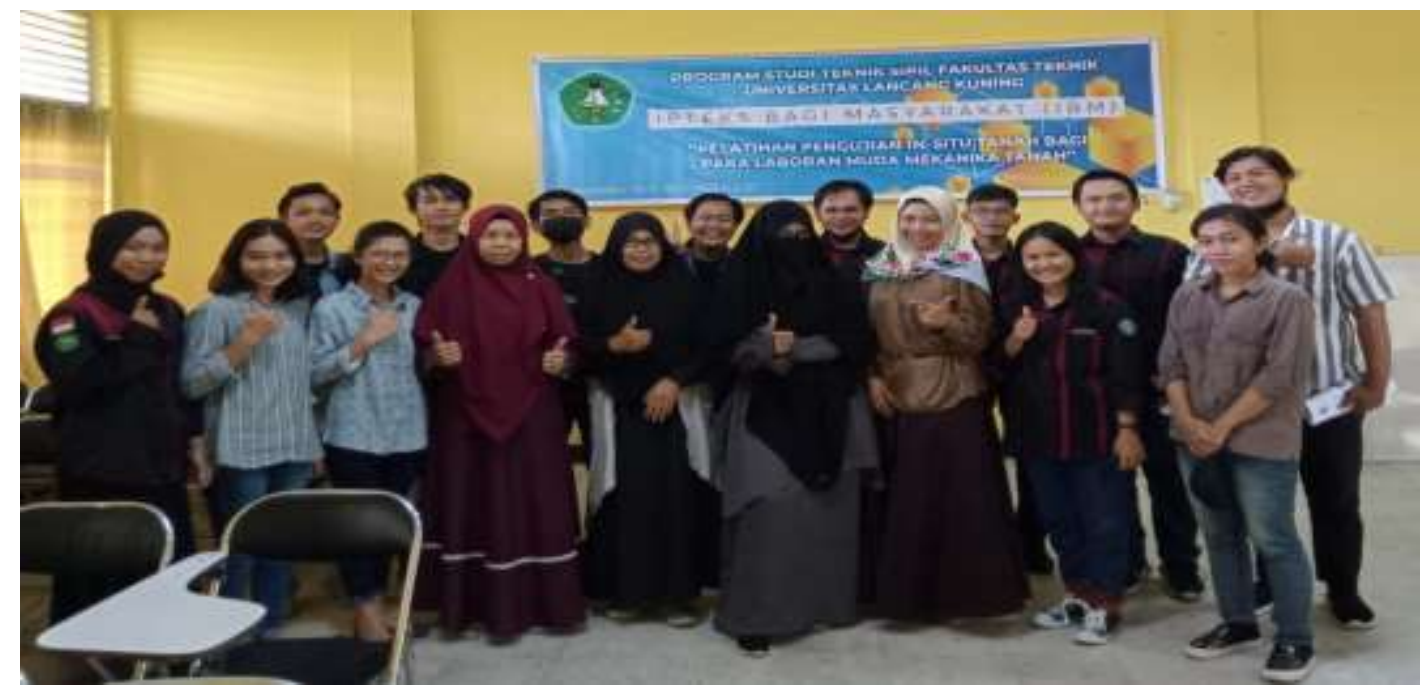

Gambar 1. Panitia,Narasumber,dan peserta Pelatihan In-situ Tanah Bagi Laboran Muda Mekanika Tanah

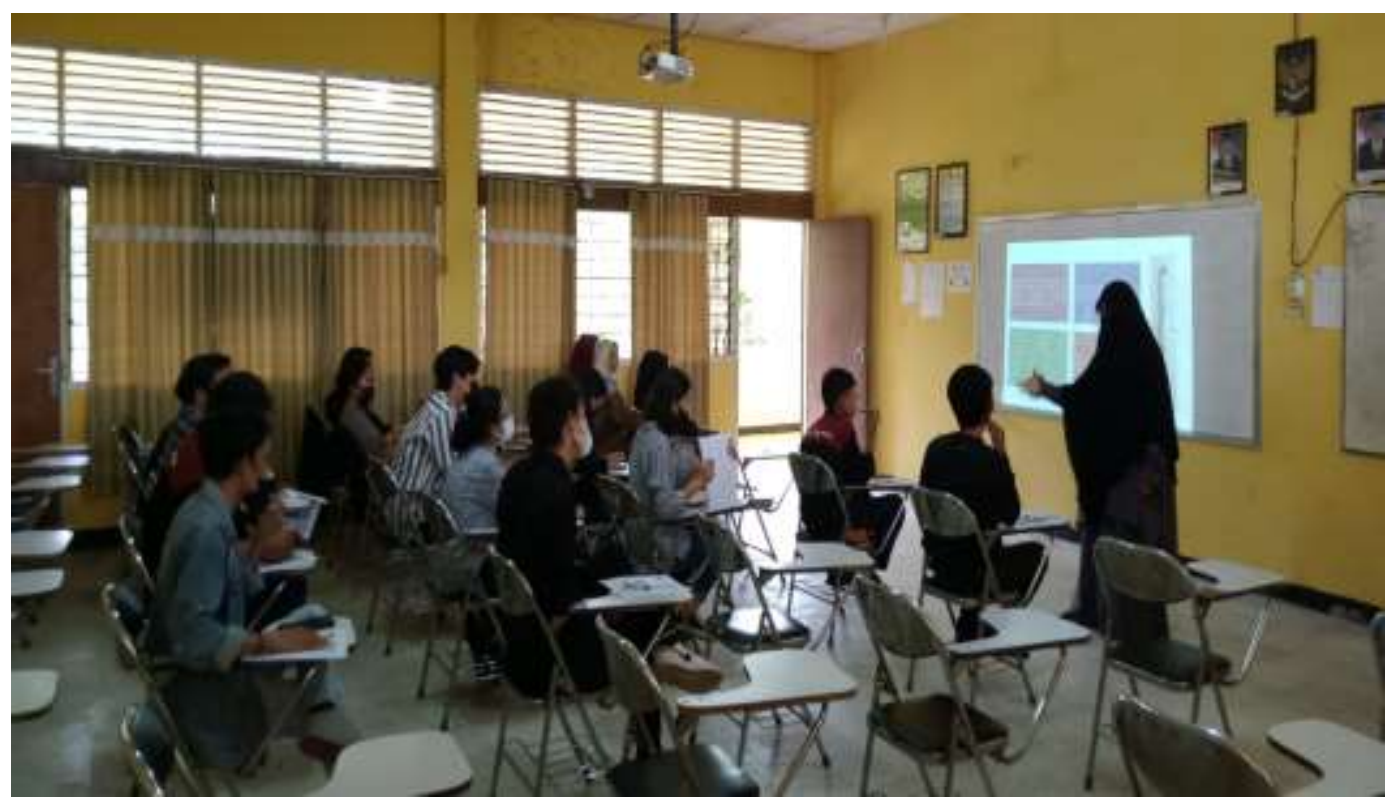

Gambar 2. Pemberian Materi Pelatihan In-situ Tanah Bagi Laboran Muda Mekanika Tanah

Setelah diberikan materi pelatihan para peserta diberikan praktek langsung bagimana cara menggunakan alat Dynamic Cone Penetrometer, alat Handbore dan alat Sandcone dilapangan. Dengan adanya praktek langsung peserta laboran muda mekanika tanah menjadi lebih paham dalam menggunakan alat sondir dengan benar sesuai dengan standar operasional prosedur (SOP) yang berlaku. 
Proses Pelaksanaan praktek pelatihan In-situ Tanah menggunakan handbore dapat dilihat pada gambar 3

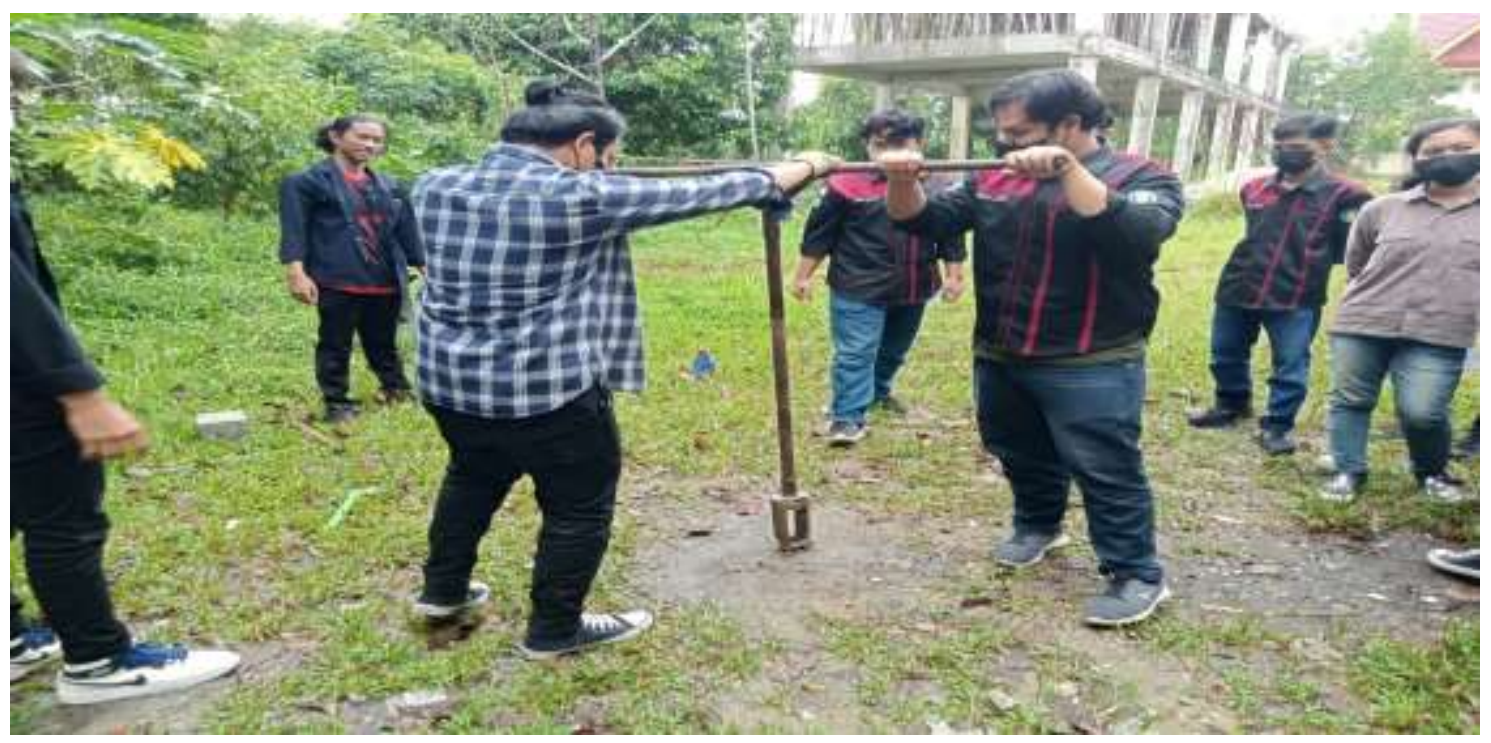

Gambar 3. Pratek Penggunaan Alat Handbore

Proses Pelaksanaan praktek pelatihan In-situ Tanah menggunakan Dynamic Cone Penetrometer dapat dilihat pada gambar 4.

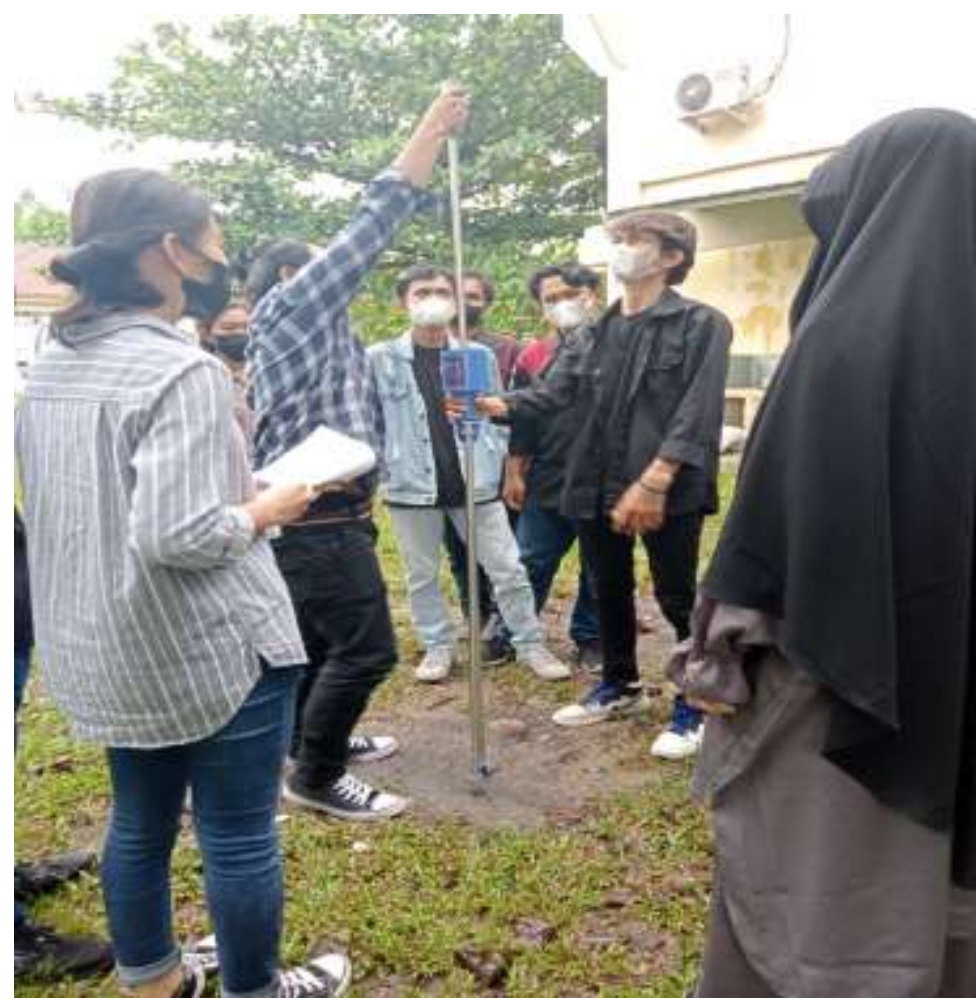

Gambar 4. Pratek Penggunaan Alat Dynamic Cone Penetrometer

Proses Pelaksanaan praktek pelatihan In-situ Tanah menggunakan sandcone dapat dilihat pada gambar 5 . 


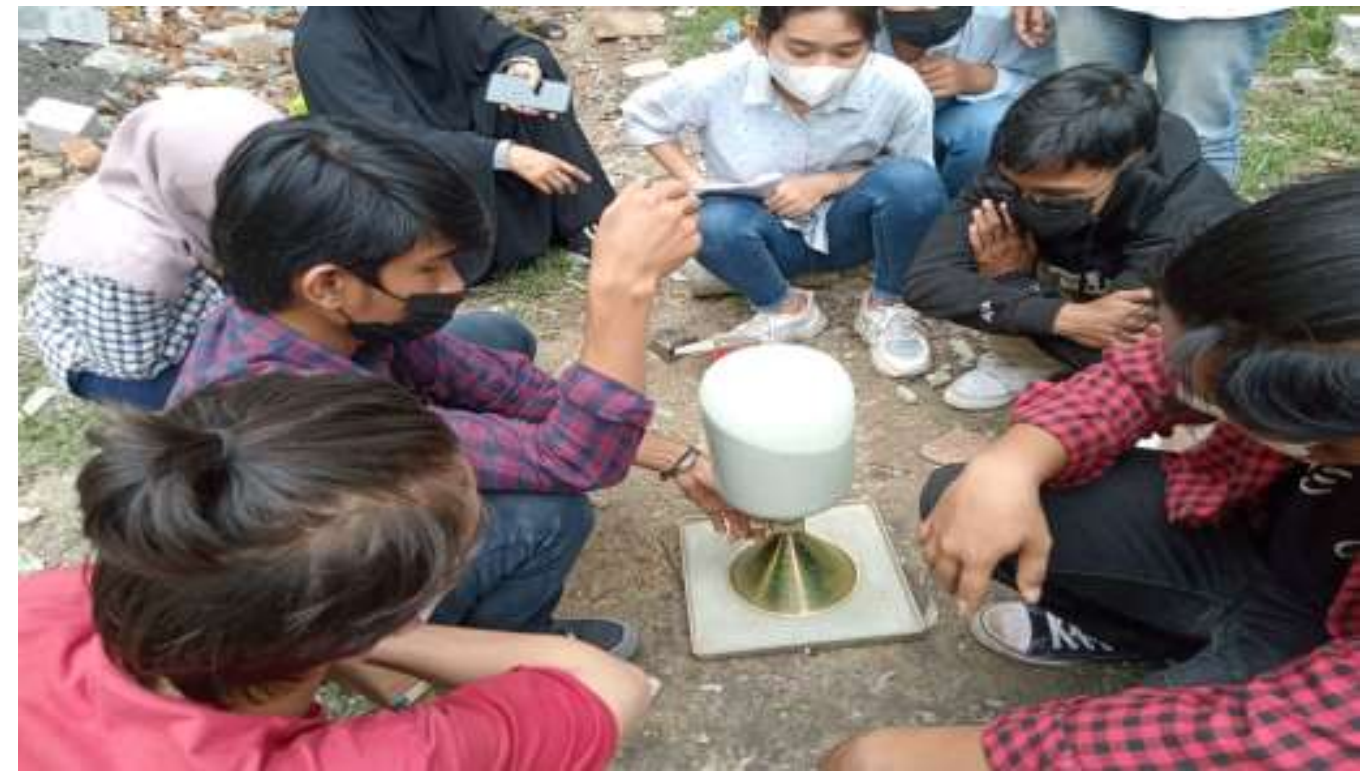

Gambar 5. Pratek Penggunaan Alat Sancone

Dari hasil pelaksanaan kegiatan pelatihan Insitu Tanah bagi Laboran Muda mekanika Tanah dapat dilihat bahwa para peserta mendapat transfer ilmu tentang pengujian Insitu-Tanah. Hal ini dapat dilihat dari gambar 3,4 dan 5, para peserta sudah dapat menggunakan alat pengujian handbore, Dynamic Cone Penetrometer dan Sancone. Setelah pelatihan ini peserta diharapkan dapat mempergunakan pengetahuan yang diperoleh selama pelatihan dengan mengimplementasikannya dalam pelaksanaan dilapangan dan diharapkan dapat mengambil keputusan yang objektif dalam penyelidikan tanah.

\section{KESIMPULAN}

Kegiatan Pengabdian masyarakat dalam bentuk pelatihan pengujian In-Situ Tanah bagi laboran mekanika tanah yang diadakan bertujuan untuk memberikan bekal informasi tentang tentang pengenalan dan penggunaan alat pengujian In-Situ seperti Dynamic Cone Penetrometer, alat Handbore dan alat Sandcone. Hasil pelatihan ini mampu meningkatkan pengetahuan peserta terhadap penggunaan alat pengujian In-situ tanah dan trik-trik dalam mengatasi permasalahan dilapangan terhadap penggunaan alat Insitu sehingga diharapkan para peserta dapat mengimplementasikan ilmu yang di dapat dalam pelaksanaan dilapangan nantinya.

\section{UCAPAN TERIMA KASIH}

Ucapan terimakasih ditujukan kepada Himatesi program studi teknik sipil universitas lancang kuning yang telah memberikan kesempatan untuk melakukan kegiatan pengabdian, dan terimakasih diucapkan kepada pimpinan fakultas teknik Universitas lancang kuning dan pimpinan Unilak lembaga penelitian dan pengabdian kepada masyarakat yang telah memberikan bantuan finansial dalam melaksanakan kegiatan ini.

\section{DAFTAR PUSTAKA}

Hadijah, I. (2015). Analisis Kepadatan Lapangan Dengan sand cone Pada Kegiatan Peningkatan Struktur Jalan Tegineneng - Batas Kota Metro. TAPAK (Teknologi Aplikasi Konstruksi): Jurnal Program Studi Teknik Sipil, 4(2), 87-92.

J.E.R. Sumampouw. (2010). Analisis pengujian CBR lapangan dan CBR laboratorium pada tanah 
dasar infrastruktur manado selatan. TEKNO, 07(52), 46-52. Retrieved from http://www.landasanteori.com/2015/09/pengertian-kreativitas-definisi-aspek.html Kementrian PUPR. Manual Petunjuk Teknis Pengujian Tanah (2021). Indonesia.

Lengkong, P. I. L., Monintja, S., Sompie, O. B. A., \& Sumampouw, J. E. R. (2013). Hubungan Nilai CBR Laboratorium dan DCP pada Tanah yang dipadatkan pada ruas Jalan Wori-Likupang Kabupaten minahasa utara. Jurnal Sipil Statik, 1(5), 368-376.

Malauw, K. anaya, Sidik, A., \& Pramudito, H. (2018). Penentuan Metode Penyelidikan Tanah / Batuan Bawah Permukaan Dan Jenis Bor, Dalam Rangka Penyiapan Tapak Bendungan Ameroro, Kabupaten Konawe, Sulawesi Tenggara. In Seminar Nasional Cendekiawan ke 14 Tahun 2018, Buku 1: "Teknik, Kedokteran Hewan, Kesehatan, Lingkungan dan Lanskap" (pp. 405-409).

N, M. H. D., \& MS, M. (2017). Analisis Kestabilan Lubang Bukaan Dengan Pengujian Flat Jack Pada Dinding Tunnel 1 Tambang Bawah Tanah PT Allied. Jurnal Bina Tambang, 5(2), 136-146.

Permatasari, S. (2018). Analisis Kepadatan Tanah Dengan Menggunakan Alat DCP (Dinamic Cone Penetration) Di Desa Sungai Loban Kabupaten Tanah Bumbu. In Seminar Nasional Riset Terapan (Vol. 5662, pp. 27-33).

Prayogo, K., \& Saptowati, H. (2016). Penyelidikan struktur dan karakteriistik tanah untuk desain Pondasi Iridiatir Gamma kapasitas 2 MCi. Jurnal Perangkat Nuklir, 10(1), 30-49.

Srihandayani, S., Studi, P., \& Dumai, T. (2019). Pengenalan Soil Investigasi Untuk Siswa SMK Bangunan Sebagai Dasar Pengetahuan Desain Pondasi. Dinamisia: Jurnal Pengabdian Kepada Masyarakat, 3(special issue juni), 166-170.

Sukirman, S. (1999). Perkerasan Lentur Jalan raya. Bandung: Nova.

Yanti, G., Zainuri, \& Megasari, S. W. (2017). Analisis Pengaruh Pelatihan Teknologi Penyondiran Pada Usaha Mikro Kontruksi Di kota pekanbaru. SIKLUS: Jurnal Teknik Sipil, 1729 (April), $39-48$. 